\title{
Análise da morfologia urbana para maximização de geração de energia fotovoltaica no Belenzinho, em São Paulo
}

\author{
Urban Morphology maximisation of Urban PV power \\ generation capacity in the São Paulo neighbourhood of \\ Belenzinho
}

\section{Carolina Girotti \\ Karin Regina de Castro Marins Arthur Hunold Lara}

\section{Resumo}

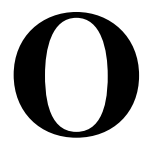

artigo analisa os arranjos morfológicos urbanos condicionantes da geração de energia fotovoltaica, no bairro do Belenzinho, em São Paulo. Foi utilizado o software 3D Rhinoceros ${ }^{\circledR}$ com os plug-ins Grasshopper $^{\circledR}$ e Diva ${ }^{\circledR}$ para modelar a variação isolada dos parâmetros urbanísticos e identificar parâmetros que maximizam ou minimizam a incidência de radiação solar na cobertura das edificações. Em seguida, utilizou-se o algoritmo genético Galapagos, com a finalidade de combinar os parâmetros urbanísticos, identificando-se os valores mais adequados quanto ao aproveitamento da radiação solar. As análises mostraram que valores intermediários de coeficiente de aproveitamento e taxa de ocupação igual a 0,70 são indicados para maximizar a geração de energia fotovoltaica na escala de vizinhança. Enquanto valores máximos permitidos pela legislação são indicados na escala da edificação. Assim, a definição de uma política energética municipal para aproveitamento fotovoltaico na cobertura de edificações passa pela análise da viabilidade de geração concentradas ou distribuídas, o que impacta em diferentes formas de apropriação na regulação da ocupação do solo.

Palavras-chave: Sistemas fotovoltaicos. Geração distribuída de energia. Morfologia urbana. Urbanismo paramétrico. Parâmetros urbanísticos.

${ }^{1}$ Carolina Girotti

1 Universidade de São Paulo São Paulo - SP - Brasil https:// orcid. org/ 0000-0001-7092-0038

${ }^{2}$ Karin Regina de Castro Marins 2 Universidade de São Paulo São Paulo - SP - Brasil

${ }^{3}$ Arthur Hunold Lara ${ }^{3}$ Universidade de São Paulo São Paulo - SP - Brasil

Recebido em 20/08/18 Aceito em 16/12/18

\section{Abstract}

This study analyses the parameters of urban morphology that condition the PV power generation capacity in a the São Paulo neighbourhood of Belenzinho. Initially, using $3 D$ Rhinoceros ${ }^{\circledR}$ software with Grasshopper ${ }^{\circledR}$ and Diva ${ }^{\circledR}$ plugings was modelled based on the isolated variation of the urban parameters to identify the best and worse scores, considering the solar radiation incidence on the rooftops of individual buildings. Thereafter, the Galapagos genetic algorithm was applied with the purpose of combining the urban parameters, identifying the most adequate values for a better use of solar radiation. The analysis carried out showed that intermediate values for plot area ratio and land coverage equal to 0.70 are more suitable for better power generation performance in the neighbourhood unit, while the maximum values allowed by legislation are more in the buildings unit. Thus, the definition of a municipal energy policy for photovoltaic application on the roof of buildings involves an analysis of concentrated or distributed generation solutions in the urban territory, and its appropriation by the land use regulation.

Keywords: Photovoltaic Systems. Distributed Generation. Urban Morphology. Urban Parameters. Urban regulation.

GIROTTI, C.; MARINS, K. R. de C.; LARA, A. H. Análise da morfologia urbana para maximização de geração de energia 7 fotovoltaica no Belenzinho, em São Paulo. Ambiente Construído, Porto Alegre, v. 19, n. 4, p. 7-22, out./ dez. 2019. ISSN 1678-8621 Associação Nacional de Tecnologia do Ambiente Construído. 


\section{Introdução}

O sistema elétrico brasileiro conta, predominantemente, com unidades centralizadas de geração de energia elétrica, de base hidrotérmica. Nos últimos anos, a construção de novas usinas hidroelétricas tem sido dificultada por motivos como a distância entre as unidades geradoras e os centros de consumo e seus impactos socioambientais (FEARNSIDE, 2006, 1999). Por tais motivos, a geração de energia descentralizada, ou seja, nos próprios centros urbanos, próxima aos consumidores, torna-se atraente, sendo um tópico de pesquisa crescente mundialmente (SARRALDE et al., 2015).

No Brasil, a geração distribuída de energia elétrica é regulamentada pela Resolução Normativa n. 482, de 17/04/2012, da Agência Nacional de Energia Elétrica (ANEEL), revisada pela Resolução Normativa n. 687, de 24/11/2015, que a tornou amplamente acessível ao consumidor final. Nos sistemas de geração distribuída de energia elétrica já existentes e nos previstos, o principal sistema de geração empregado é o solar fotovoltaico (BRASIL, 2015, 2012)

Entretanto, cidades brasileiras não foram planejadas para gerarem energia solar fotovoltaica, o que prescinde da avaliação e da adequação dos parâmetros que orientam a definição, sobretudo da forma urbana, constantes nas principais políticas urbanas, especialmente a lei de parcelamento, uso e ocupação do solo (FUTCHER; MILLS, 2013; MARINS; ROMÉRO, 2013, 2012).

A definição da forma urbana, para garantir acesso satisfatório à radiação solar, que influencia as condições de insolação, deve-se principalmente à densidade urbana (SCALCO; PEREIRA; RIGATTI, 2010). A densidade urbana estabelece uma relação entre o número de pessoas por superfície ocupada e detém relação com a densidade construída, que se refere à área total construída, pela área de solo considerada (HARGREAVES et al., 2017; NG et al., 2011; HUI, 2001). No presente artigo, a densidade construída é analisada pelo coeficiente de aproveitamento (C.A.) e pela taxa de ocupação do solo (T.O.).

O C.A. define a área construída total, pois é um multiplicador que, quando aplicado à área do lote e dividido pela área do pavimento-tipo (área computável), resulta na quantidade de pavimentos que terá o empreendimento; já a T.O. é a divisão entre a área de projeção da edificação e a área do lote (MUNIZ-GÄAL et al., 2018). Os parâmetros urbanísticos definem, em geral, T.O. máxima e C.O. mínimos e máximos para cada lote, em função da zona urbana. Dessa forma, a densidade urbana construída condiciona o acesso e a intensidade da radiação solar no ambiente urbano.

Internacionalmente, modelos estatísticos na escala de vizinhança foram analisados, com o propósito de explorar relações entre a forma urbana e o potencial de geração de energia fotovoltaica em centros urbanos, precisamente na área metropolitana de Londres (SARRALDE et al., 2015). Este estudo analisa variáveis da morfologia urbana - densidade construída e distância entre edificações - em uma amostra com edificações geminadas, edificações com o mesmo gabarito de altura e edificações que foram convertidas em áreas permeáveis, tornando-se, assim, vãos livres entre as edificações. Os autores chegam a uma configuração morfológica baseada nas variáveis citadas acima, para Londres, que traz o aumento geral de $9 \%$ dos níveis de radiação solar na cobertura das edificações da área estudada. Como os autores realizam apenas a análise combinada dos parâmetros avaliados, não é possível saber, nesse estudo, qual parâmetro possui melhor resposta em relação ao nível de radiação solar.

Já no contexto brasileiro, Martins et al. (2016) realizaram um estudo na cidade de Maceió, mostrando que maiores distâncias entre edificações proporcionam menores obstruções causadas por sombreamentos, aumentando o albedo e, consequentemente, a disponibilidade de radiação solar e a geração de energia solar fotovoltaica em um assentamento urbano. Para os autores, a consequência negativa de diminuir as obstruções e consequentemente 0 sombreamento nas edificações, em cidades de clima tropical é o aumento da radiação térmica, que contribui para o efeito ilha de calor e pode trazer, dentre outros, desconforto térmico nos espaços externos.

Martins et al. (2014), em um estudo na cidade de Maceió, defendem que a distância entre as edificações é o parâmetro morfológico urbano que melhor condiciona o acesso da radiação solar. Os autores destacam ainda a importância da área formada entre o gabarito de altura da edificação e o limite do lote: quanto maior o gabarito da edificação, maior será a radiação solar recebida. Os autores ressaltam também a importância da área de projeção da edificação, que influencia na área de cobertura e, consequentemente, na disponibilidade de espaço destinado à aplicação de painel fotovoltaico.

O objetivo do presente artigo é analisar os arranjos da forma urbana que condicionam a capacidade de geração de energia fotovoltaica na cobertura das edificações, em escala de unidade de vizinhança, no 
Município de São Paulo, tomando por estudo de caso o bairro do Belenzinho, que passa por amplo processo de adensamento urbano e verticalização. $\mathrm{O}$ presente estudo analisa apenas a incidência de irradiação solar horizontal, ignorando qualquer inclinação que os painéis fotovoltaicos possam ter. Entende-se que a análise da inclinação ideal dos painéis fotovoltaicos é apropriada para a escala do edifício, mediante modelagem em ferramentas suplementares.

\section{Caracterização da área de estudo: Belenzinho - São Paulo}

O Belenzinho está situado na zona leste da capital paulista e foi escolhido por compor os novos "Eixos de Estruturação da Transformação Urbana" (EETUs) e estar localizado próximo ao centro de São Paulo. Os EETUs propostos no Plano Diretor do Município de São Paulo de 2014 incentivam o adensamento onde há acesso facilitado à rede de infraestrutura urbana, como transporte público, água, esgoto, rede elétrica e coleta de resíduos sólidos (PREFEITURA..., 2014).
A escala de trabalho é a da unidade de vizinhança, pois possibilita realizar um estudo de mudanças na forma urbana e avaliar as condições de aproveitamento do potencial fotovoltaico. Segundo Walton et al. (2007), uma unidade de vizinhança tem cerca de 50 hectare e deve estar organizada de forma integrada e dinâmica, proporcionando acesso a facilidades cotidianas com variedade suficiente por meio da caminhada e disponibilidade de lugares e espaço para realização das diversas atividades. Sendo assim, o perímetro analisado envolve a Av. Álvaro Ramos, Rua Elói Cerqueira, Rua Passos, Av. Celso Garcia e o eixo da linha vermelha do metrô, conforme ilustra a Figura 1.

Neste artigo, analisou-se o cenário atual de ocupação frente a um possível cenário morfológico evolutivo da área de estudo. Foram selecionados cinco lotes com potencial de transformação do uso e ocupação do solo em curto prazo. Os lotes analisados são atualmente ocupados com galpões e foram selecionados por constituírem estruturas com grande facilidade de transformação e possuírem uma área de intervenção considerável em apenas um ou poucos imóveis.

Figura 1 - Identificação da área de estudo e dos lotes analisados

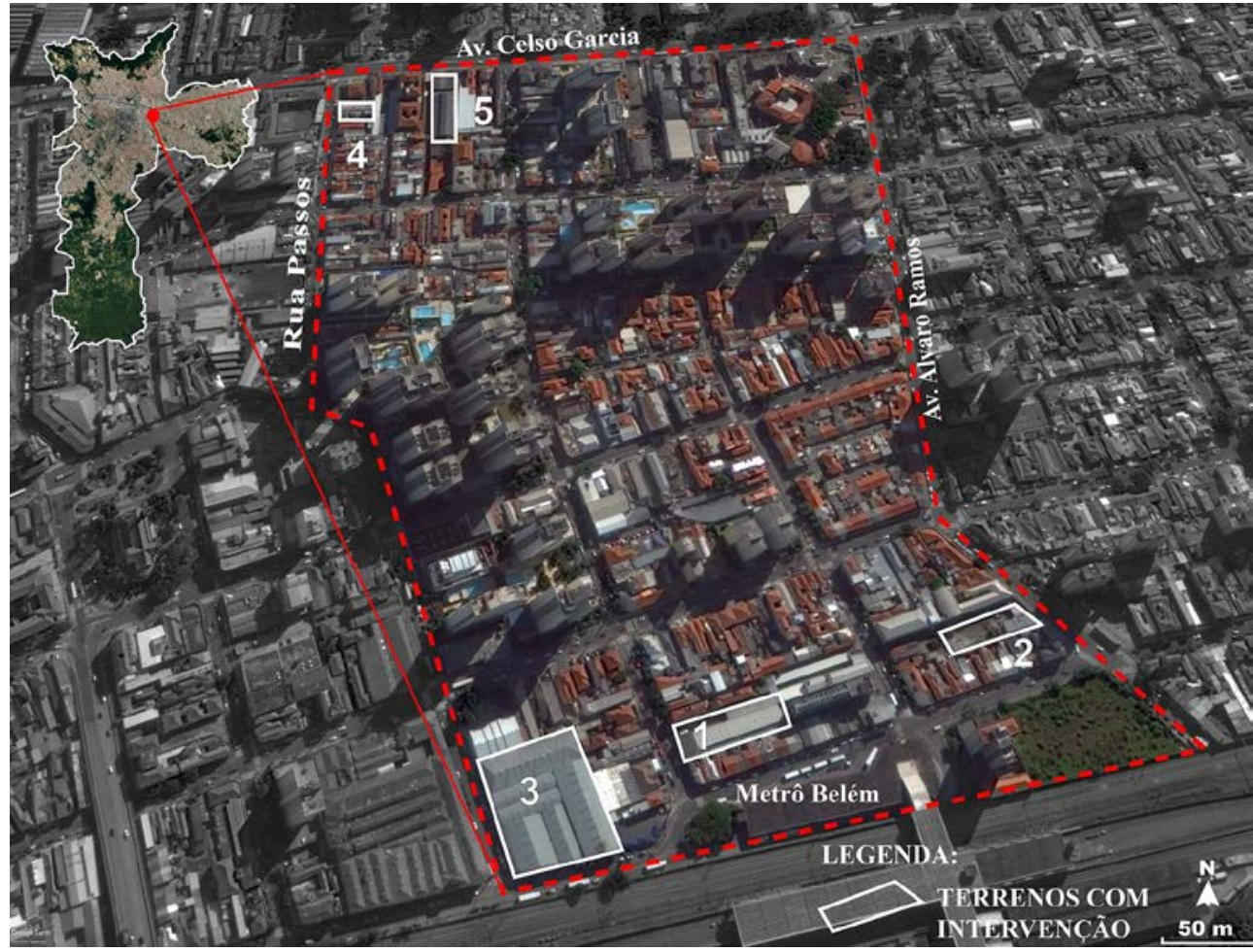

Fonte: elaborado pelos autores, a partir de Google Earth (GOOGLE, 2017). 


\section{Método de análise}

Para este estudo foi concebida uma programação paramétrica envolvendo a representação dinâmica da morfologia urbana e respectiva simulação de incidência de radiação solar, no estudo de caso.

As ferramentas de modelagem utilizadas para suportar a análise dos aspectos morfológicos urbanos condicionantes da geração de energia solar fotovoltaica foram o programa de desenho tridimensional Rhinoceros ${ }^{\circledR}$ (ROBERT..., 2012a), associado aos plug-ins Grasshopper $^{\circledR}{ }^{1}$ (ROBERT..., 2012b), Diva ${ }^{\circledR 2}$ (SOLEMMA, 2016) e algoritmo genético Galapagos ${ }^{3}$. As ferramentas foram selecionadas com base nas seguintes justificativas:

(a) o Rhinoceros ${ }^{\circledR}$ possui capacidade de interoperabilidade ampliada através de plug-ins, o que o torna flexível para uso em diversos tipos de projetos e problemas (SANTOS; AUER; SOUZA, 2017; ANTON; TǍNASE, 2016; GAVIRIA; PEREIRA; MIZGIER, 2013);

(b) o Grasshopper ${ }^{\circledR}$ é um editor algoritmo visual, que viabiliza a programação com a representação dinâmica dos elementos urbanos (SANTOS; AUER; SOUZA, 2017; ANTON; TǍNASE, 2016; GAVIRIA; PEREIRA; MIZGIER, 2013); e

(c) a análise energética foi incorporada à construção do projeto paramétrico, por meio do plug-in Diva ${ }^{\circledR}$; sendo assim, a análise energética contribui ativamente para o processo de análise morfológica (ANTON; TǍNASE, 2016; GAVIRIA; PEREIRA; MIZGIER, 2013).

Além de plug-ins dedicados à análise energética, foi implementado um algoritmo genético no Grasshopper $^{\circledR}$, o Galapagos, que busca a configuração que melhor atende à maximização ou minimização para um dossel imposto pela programação do usuário.

Nessa pesquisa, os critérios são os parâmetros urbanísticos, C.A. e T.O., bem como o ângulo da edificação e os níveis de radiação solar. Tais parâmetros urbanísticos são os "genomas" de pesquisa no algoritmo genético Galapagos. Dessa forma, o solucionador evolutivo Galapagos determina os "sobreviventes", ou seja, aqueles parâmetros urbanísticos que melhor atendem à maximização da forma urbana, para obtenção dos melhores valores de radiação solar, conforme ilustra a Figura 2.

Para analisar o cenário evolutivo da morfologia urbana dos lotes selecionados na área de estudo, foi construído um algoritmo no Grasshopper ${ }^{\circledR}$, por meio das etapas detalhadas a seguir e também indicadas na visão geral do algoritmo, ilustrada na Figura 10

\section{Figura 2 - Visão detalhada do otimizador algoritmo genético Galapagos}

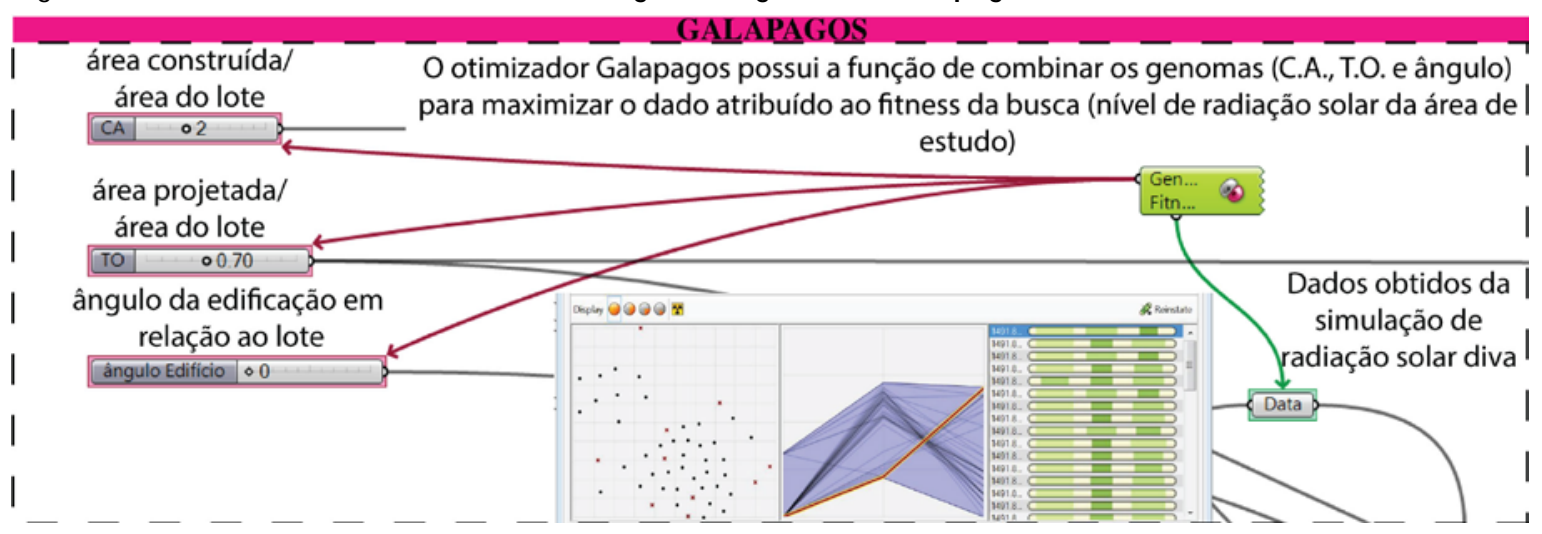

${ }^{1}$ Grasshopper ${ }^{\circledR}$ é um plug-in que possibilita modelagem paramétrica dentro do software Rhinoceros ${ }^{\circledR}$.

${ }^{2}{ }^{2}{ }^{2}{ }^{\circledR}{ }^{\circledR}$ é um plug-in de simulação energética, que simula os níveis de radiação solar de uma determinada área. ${ }^{3}$ Galapagos é um algoritmo genético que busca soluções que
resolvam simultaneamente e satisfatoriamente os diferentes
objetivos de um problema através de uma combinação de
algoritmos (MARTINO; CELANI, 2014). 


\section{Primeira etapa: aplicação do plug-in Diva $^{\circledR}$}

Denominado no algoritmo como "SOL DIVA", refere-se à localização do sol no modelo tridimensional. Os parâmetros de entrada no algoritmo são a representação tridimensional da área de estudo na plataforma Rhinoceros ${ }^{\circledR}$, com base em dados levantados manualmente através da ferramenta Google Earth $^{\circledR}$ (GOOGLE, 2017) e em dados georreferenciados disponíveis na plataforma GeoSampa, da Prefeitura de São Paulo (PREFEITURA..., 2017). Também foi utilizado o arquivo .epw, de São Paulo, que possui funcionalidade de uma carta solar. Foi necessário utilizar um raio de análise de 600 metros para o estudo de caso apresentado. O mês escolhido para a localização do sol na simulação foi junho, pois é quando o sol atinge a maior distância angular em relação ao plano da linha do Equador, devido ao solstício de inverno (portanto, período crítico de acesso da radiação solar à região estudada). O horário definido para a simulação foi 15 horas, por corresponder ao pico de demanda de eletricidade (EMPRESA..., 2017). A Figura 3 ilustra o algoritmo do "Sol Diva”.

\section{Segunda etapa: simulação dos níveis de radiação solar na área de estudo, na configuração urbana atual}

Após a aplicação do "sol Diva” na área de estudo, foi possível realizar a simulação do nível de radiação solar, na configuração urbana atual da área estudada. A simulação foi realizada a partir das edificações tridimensionais modeladas no software Rhinoceros $^{\circledR}$, e por uma opção do Diva ${ }^{\circledR}$ denominada "radiation map" ${ }^{4}$, conforme ilustra a Figura 4.

\section{Terceira etapa: simulação da variação individual do coeficiente de aproveitamento e da taxa de ocupação do solo}

Os valores dos parâmetros urbanísticos foram definidos conforme as variações permitidas para cada lote analisado, seguindo o parcelamento, uso e ocupação do solo do Município de São Paulo (PREFEITURA..., 2016).

A variação individual dos parâmetros urbanísticos foi realizada visando à possibilidade de visualização dos impactos positivos e negativos em relação aos níveis de radiação solar. A simulação é dada em $\mathrm{kWh} / \mathrm{m}^{2}$.ano e em radiação solar incidente total, permitindo identificar o real impacto da morfologia urbana na intensidade da radiação solar incidente na cobertura de cada empreendimento analisado.

O algoritmo da terceira etapa combina os algoritmos energéticos das primeiras etapas com algoritmos morfológicos elaborados e intitulados "Projeção Edificação", "Gabarito Edificação" e "Localização Edificação no Lote”.

No “Projeção Edificação”, o lote definido no programa Rhinoceros ${ }^{\circledR}$ e os valores numéricos de T.O. são os parâmetros de entrada, conforme ilustra a Figura 5.

Em "Gabarito da Edificação", é definida a verticalidade do empreendimento analisado (gabarito de altura), com o parâmetro numérico de entrada C.A., conforme ilustra a Figura 6.

Em “Localização Edificação no Terreno”, é calculado qual o melhor posicionamento do empreendimento no terreno. O ângulo da edificação é um parâmetro numérico criado para melhor posicionar a edificação no lote, considerando os níveis de radiação solar, conforme ilustra a Figura 7.

Figura 3 - Visão detalhada do algoritmo proposto "Sol Diva"

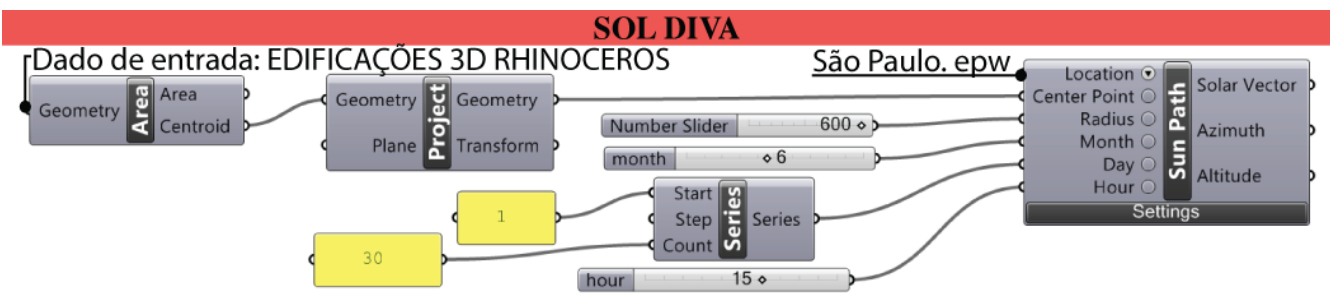

${ }^{4}$ Radiation map: gera renderizações de exposição solar, calcula 0 potencial de energia fotovoltaica e explora mapas dinâmicos através de cores na janela de visualização do Rhinoceros (SOLEMMA LLC, 2018). 
Figura 4 - Visão detalhada do algoritmo proposto "Mapa solar Diva"

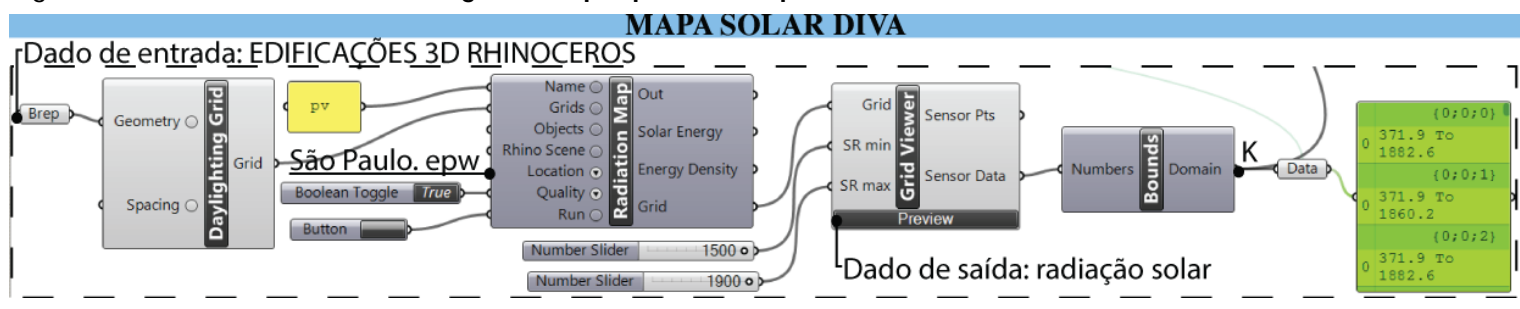

Figura 5 - Visão detalhada do algoritmo proposto "Projeção Edificação"

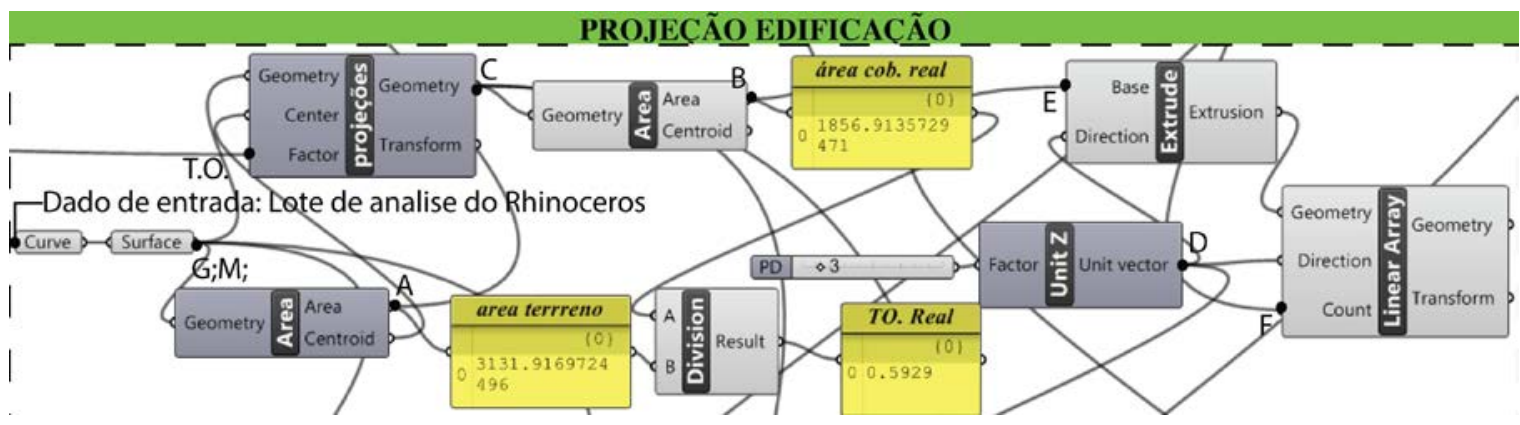

Figura 6 - Visão detalhada do algoritmo proposto "Gabarito Edificação"

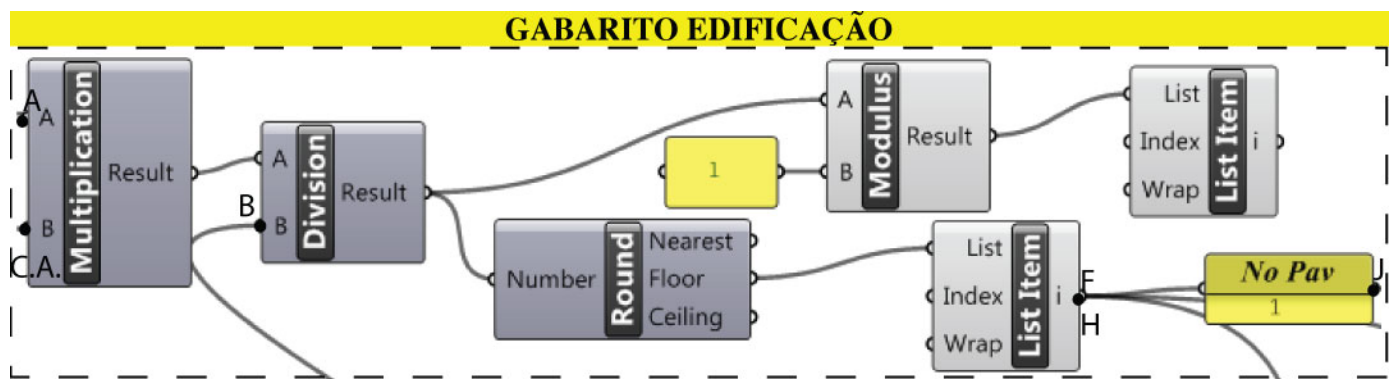

Figura 7 - Visão detalhada do algoritmo proposto “Localização Edificação no Lote”

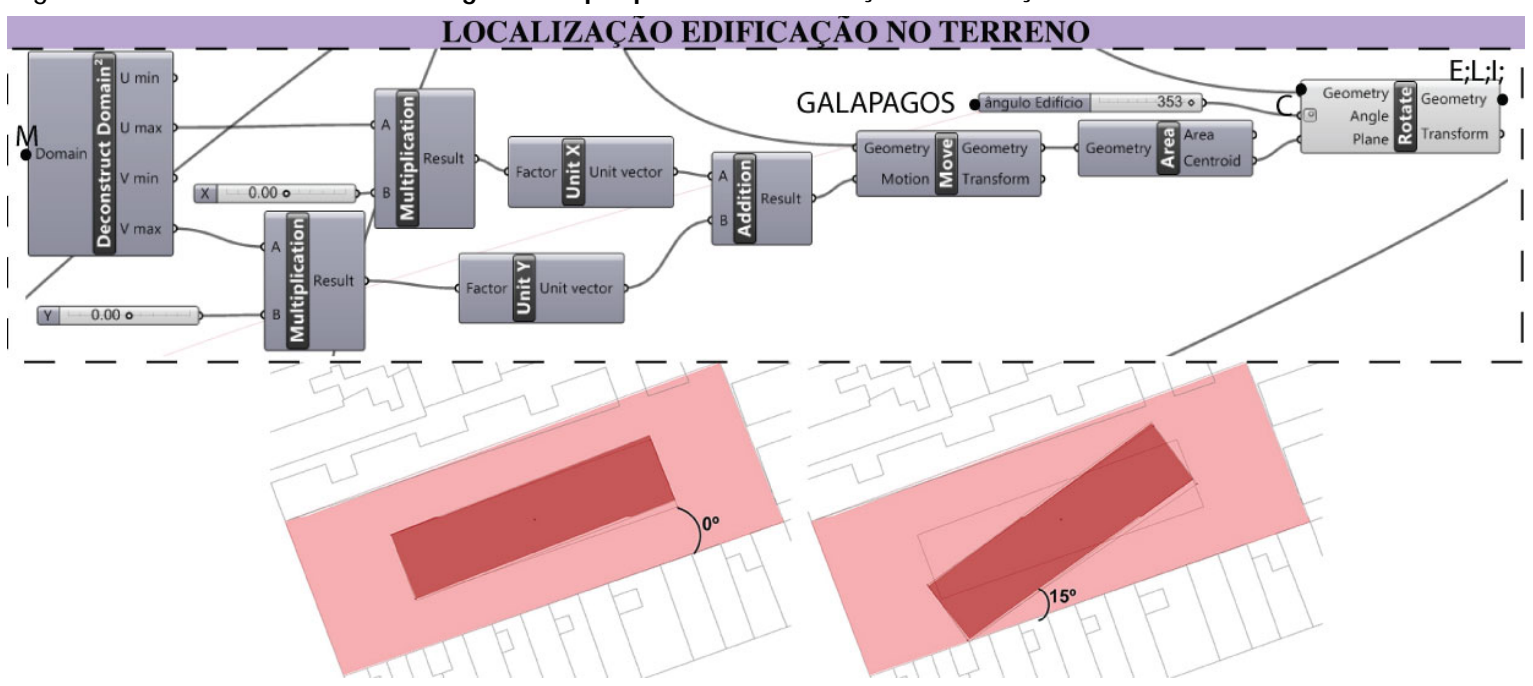

O dado de saída da elaboração dos algoritmos morfológicos é o "Novo Empreendimento", onde é aplicado um novo “mapa de radiação Diva”, para calcular a radiação solarincidente sobre a cobertura do volume construído criado no terreno analisado, conforme ilustra a Figura 8. 


\section{Quarta etapa: aplicação do algoritmo genético Galapagos}

O algoritmo genético Galapagos foi aplicado ao resultado obtido na quarta etapa, a fim de combinar os parâmetros urbanísticos analisados anteriormente com o ângulo da edificação, bem como com os níveis de radiação solar. Assim, identificam-se os valores pertinentes para maximizar o aproveitamento da radiação solar, para cada amostra de lote em estudo.
Um algoritmo denominado "Filtro Recuo" foi criado no Grasshopper ${ }^{\circledR}$, para que a edificação analisada, mesmo rotacionada, respeite o perímetro do lote, observando os recuos mínimos. Ou seja, quando o empreendimento possuir mais que três pavimentos, ou dez metros de altura, é respeitado o recuo mínimo de três metros, conforme detalhado pela Figura 9.

\section{Figura 8 - Visão detalhada do algoritmo proposto “Novo Empreendimento"}

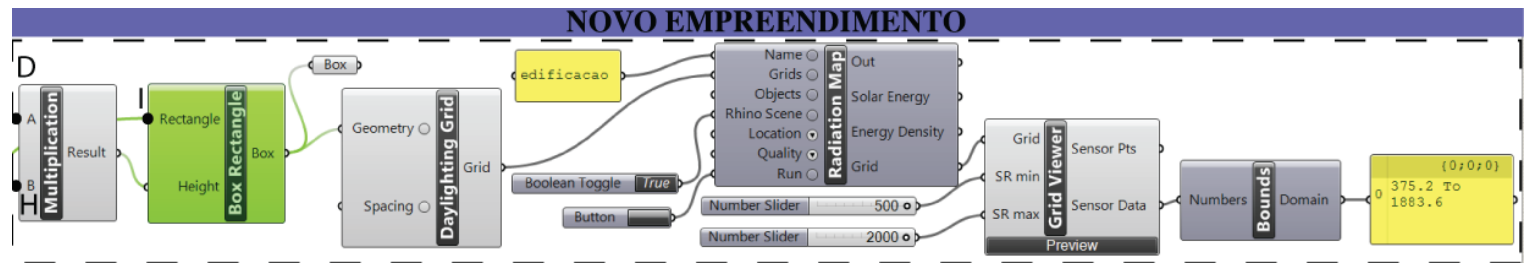

Figura 9 - Visão detalhada do algoritmo "Filtro Recuo" e ângulo da edificação em relação ao lote

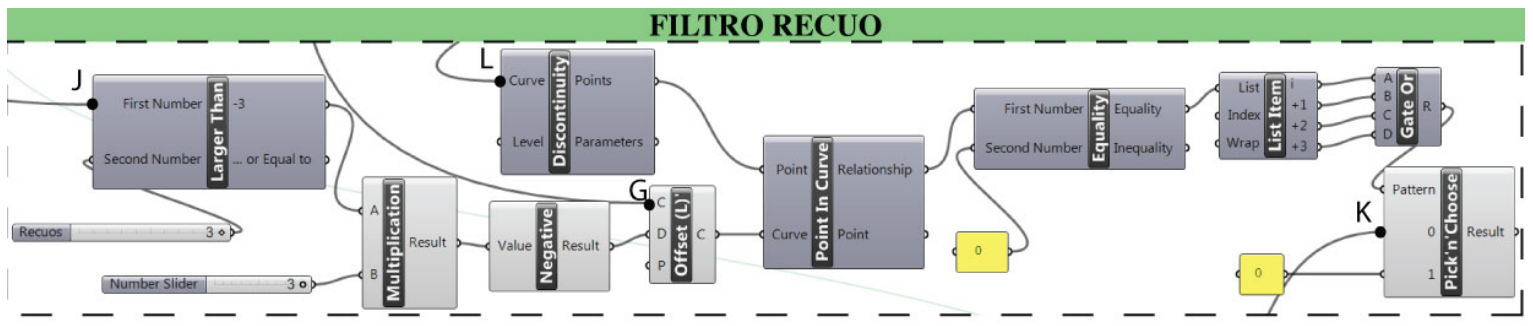

Figura 10 - Visão geral do algoritmo proposto e seus blocos algorítmicos, desenvolvidos no programa Grasshopper

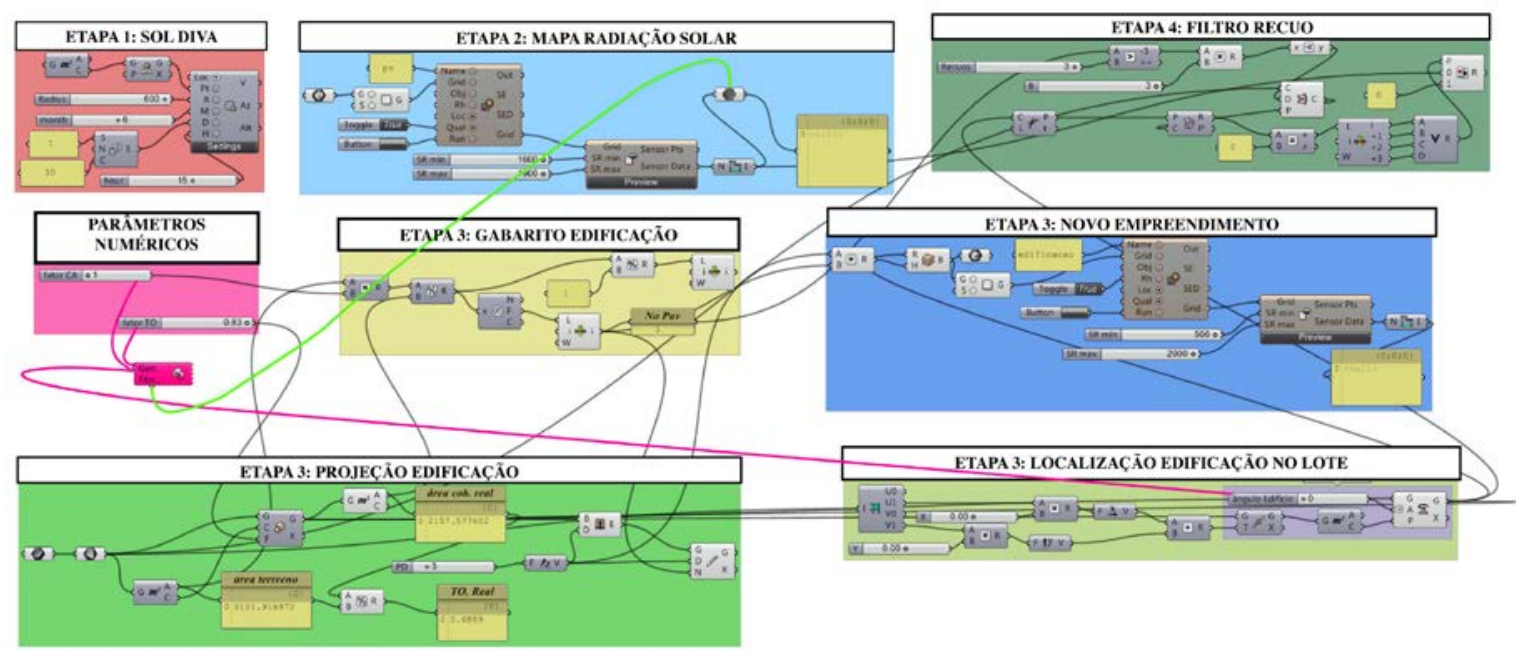


O lote 4 e 5 estão localizados na Rua Passos e na Avenida Celso Garcia, respectivamente, conforme ilustrado na Figura 1. Pertencem à Zona Eixo de Estruturação Urbana Prevista (ZEUP), tendo C.A. mínimo de 0,5, C.A. básico de 1,0 e C.A. máximo de 2,0. O lote igual ou maior que $500 \mathrm{~m}^{2}$ possui T.O. máxima de 0,70 (lote 5) e o lote com menos que 500 $\mathrm{m}^{2}$ possui T.O. máxima de 0,85 (lote 4).

O resultado das análises realizadas no lote 1 , em termos da radiação solar incidente por metro quadrado e da radiação solar incidente por área total de cobertura, é mostrado na Tabela 1.

Tabela 1 - Lote 1: valores de incidência do nível de radiação solar por $\mathbf{m}^{2}$ e cálculo da radiação solar incidente total

\begin{tabular}{|c|c|c|c|c|c|c|c|c|}
\hline & C.A. & T.O. & Âng. & $\begin{array}{c}\text { Radiação } \\
\text { solar } \\
\left(\mathbf{k W h} / \mathbf{m}^{2} /\right. \\
\text { ano) }\end{array}$ & $\% *$ & $\begin{array}{c}\text { Área de } \\
\text { cobertura } \\
\left(\mathbf{m}^{2}\right)\end{array}$ & $\begin{array}{c}\text { Radiação solar } \\
\text { (kWh/área de } \\
\text { cobertura/ano) }\end{array}$ & $\% *$ \\
\hline C.A. 4; T.O. 0,70 & 4 & 0,70 & $0^{\circ}$ & 1.857 & $1 \%$ & $1.153,0$ & 2.141 .121 & $39 \%$ \\
\hline С.A. 4; T.O. 0,60 & 4 & 0,60 & $0^{\circ}$ & 1.858 & $1 \%$ & 993,0 & 1.844.994 & $19 \%$ \\
\hline C.A. 4; T.O. 0,50 & 4 & 0,50 & $0^{\circ}$ & 1.885 & $3 \%$ & 820,0 & 1.545 .700 & $0 \%$ \\
\hline C.A. 2; T.O. 0,70 & 2 & 0,70 & $0^{\circ}$ & 1.842 & $0 \%$ & $1.153,0$ & 2.123 .826 & $37 \%$ \\
\hline C.A. 1 ; T.O. 0,70 & 1 & 0,70 & $0^{\circ}$ & 1.833 & $0 \%$ & $1.153,0$ & 2.113 .449 & $37 \%$ \\
\hline Galapagos & 4 & 0,70 & $0^{\circ}$ & 1.857 & $1 \%$ & $1.153,0$ & 2.141 .121 & $39 \%$ \\
\hline
\end{tabular}

Nota: *\% percentual de incremento dos ganhos de radiação solar em relação ao pior resultado.

A análise das simulações da variação dos parâmetros isolados do lote 1 mostra que a variação da taxa de ocupação para 0,50 gerou melhor resposta em relação à radiação solar, quando considerado o $\mathrm{kWh} / \mathrm{m}^{2}$ ano. A melhor resposta com a variação da taxa de ocupação do solo mostra que a distância entre as edificações vizinhas amplia o acesso da radiação solar à cobertura dos empreendimentos, já que diminui o sombreamento causado pelas edificações vizinhas. Além disso, ela aumenta o gabarito de altura do empreendimento analisado, pois quando se diminui a taxa de ocupação mantendo-se o coeficiente de aproveitamento no máximo permitido, a área de projeção horizontal é reduzida, necessitando-se, assim, aumentar o número de pavimentos para se manter o coeficiente de aproveitamento previsto. O gabarito de altura maior beneficia, na escala do empreendimento, o nível de radiação solar recebido.

Porém, quando se analisa a radiação solar total incidente sobre a cobertura, a redução da taxa de ocupação se destaca como sendo o parâmetro mais sensível. Isso ocorre porque a redução da taxa de ocupação implica diminuição da área total de cobertura (área de projeção horizontal da edificação) exposta à radiação solar. Quando se analisa a radiação solar total incidente sobre a cobertura, as variações com índices urbanísticos máximos permitidos pela legislação vigente no Município de São Paulo indicam melhor desempenho, por possuírem maior área de cobertura, combinada com maior gabarito de altura, dentro dos valores dos parâmetros urbanísticos permitidos pela legislação.

O Galapagos aplicado ao lote 1 manteve o coeficiente de aproveitamento e a taxa de ocupação nos valores máximos permitidos pela legislação, sendo 4 e 0,70, respectivamente, deixando a edificação com densidade construída maior e ângulo da edificação em 0 grau. $\mathrm{O}$ aumento da densidade construída, por meio da taxa de ocupação, aumenta a área de cobertura do empreendimento, favorecendo, assim, a geração de energia fotovoltaica, conforme já relatado. É importante ressaltar que o algoritmo genético Galapagos encontrou a melhor combinação entre os parâmetros urbanísticos, para obtenção de melhores níveis de radiação solar, não apenas do empreendimento analisado, e sim de sua vizinhança como um todo, conforme ilustrado na Figura 11. Nota-se, por meio do comparativo entre os níveis de radiação solar do cenário morfológico atual de ocupação frente ao cenário morfológico evolutivo, que este maximiza os níveis de incidência da radiação solar na vizinhança imediata ao empreendimento, e também no próprio lote analisado. Os valores são bastante expressivos no lote 1 , pois, por atualmente se encontrar vago, sofre com o sombreamento dos empreendimentos vizinhos.

O resultado das análises realizadas no lote 2, em termos da radiação solar incidente por metro quadrado e da radiação solar incidente por área total de cobertura, é mostrado na Tabela 2. 
A análise das simulações de variação dos parâmetros isolados do lote 2 mostra que a variação da taxa de ocupação para 0,50 gerou melhor resposta em relação à radiação solar, quando é considerado o $\mathrm{kWh} / \mathrm{m}^{2}$ ano. A melhor resposta com a variação da taxa de ocupação do solo mostra que a distância entre as edificações vizinhas amplia o acesso da radiação solar das superfícies dos empreendimentos, já que diminui o sombreamento causado pelas edificações vizinhas. Também aumenta o gabarito de altura do empreendimento analisado, pois, quando se diminuiu a taxa de ocupação e se mantém o coeficiente de aproveitamento no máximo permitido, a área de projeção horizontal diminuiu, necessitando, assim, aumentar o número de pavimentos para se manter o coeficiente de aproveitamento previsto. O gabarito de altura maior beneficia, na escala do empreendimento, o nível de radiação solar recebido.

Porém, quando é analisada a radiação solar total incidente sobre a cobertura, a redução da taxa de ocupação se destaca como sendo o parâmetro mais sensível. Isso ocorre porque a redução da taxa de ocupação diminui a área total de cobertura (área de projeção horizontal da edificação) exposta à radiação solar. Assim, as variações com T.O. elevadas são as que resultaram em melhor desempenho, sendo a variação com C.A. máximo (maior verticalização, portanto maior exposição) ligeiramente mais eficiente que a variação com C.A. intermediário.

\section{Figura 11 - Comparação da radiação solar no lote 1 e vizinhança imediata, cenário morfológico atual de ocupação e cenário morfológico evolutivo (Galapagos)}

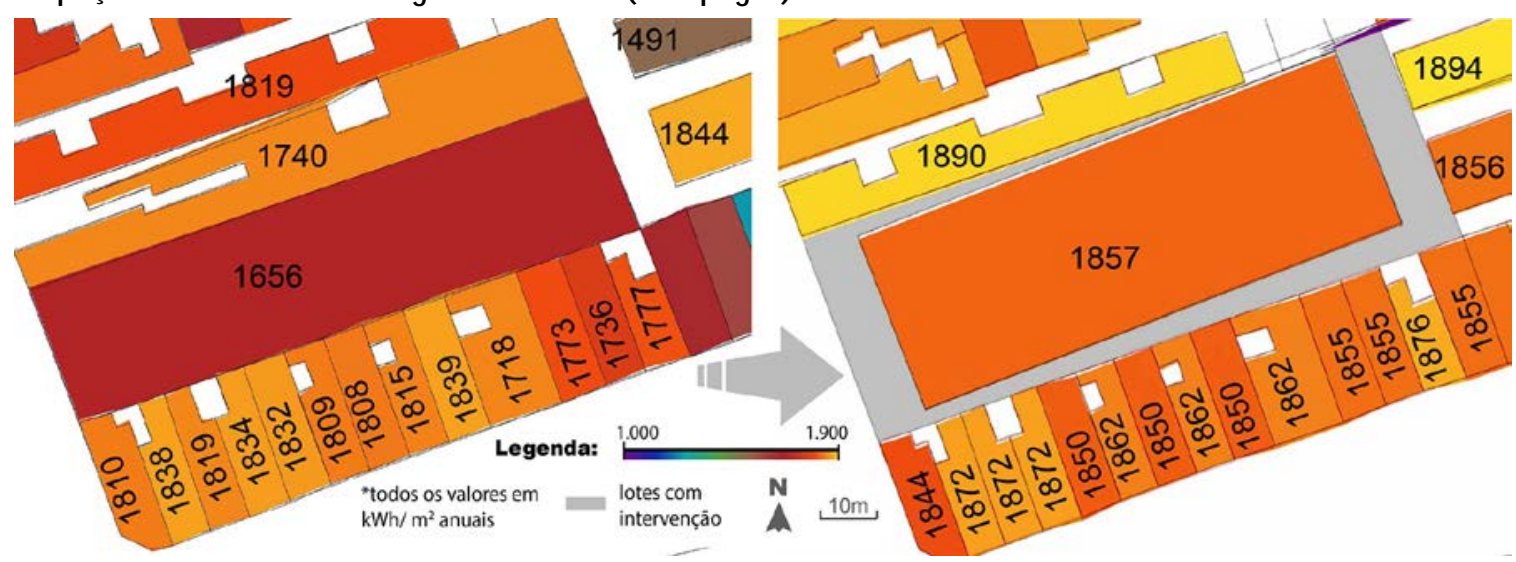

Tabela 2 - Lote 2: valores de incidência do nível de radiação solar por $\mathbf{m}^{\mathbf{2}}$ e cálculo da radiação solar incidente total

\begin{tabular}{|c|c|c|c|c|c|c|c|c|}
\hline & C.A. & T.O. & Âng. & $\begin{array}{c}\text { Radiação } \\
\text { solar } \\
\left(\mathbf{k W h} / \mathbf{m}^{2} /\right. \\
\text { ano) }\end{array}$ & $\% *$ & $\begin{array}{c}\text { Área de } \\
\text { cobertura } \\
\left(\mathbf{m}^{2}\right)\end{array}$ & $\begin{array}{c}\text { Radiação solar } \\
\text { (kWh/área de } \\
\text { cobertura/ano) }\end{array}$ & $\% *$ \\
\hline C.A. 4; T.O. 0,70 & 4 & 0,70 & $0^{\circ}$ & 1.865 & $1 \%$ & 846,0 & 1.577 .790 & $39 \%$ \\
\hline C.A. 4; T.O. 0,60 & 4 & 0,60 & $0^{\circ}$ & 1.874 & $2 \%$ & 728,0 & 1.364.272 & $20 \%$ \\
\hline С.А. 4; T.O. 0,50 & 4 & 0,50 & $0^{\circ}$ & 1.885 & $2 \%$ & 601,7 & 1.134.205 & $0 \%$ \\
\hline C.A. 2; T.O. 0,70 & 2 & 0,70 & $0^{\circ}$ & 1.864 & $1 \%$ & 846,0 & 1.576 .944 & $39 \%$ \\
\hline C.A. 1 ; T.O. 0,70 & 1 & 0,70 & $0^{\circ}$ & 1.844 & $0 \%$ & 846,0 & 1.560 .024 & $38 \%$ \\
\hline Galapagos & 2 & 0,70 & $0^{\circ}$ & 1.864 & $1 \%$ & 846,0 & 1.576 .944 & $39 \%$ \\
\hline
\end{tabular}

Nota: *\% percentual de incremento dos ganhos de radiação solar em relação ao pior resultado. 
O Galapagos, aplicado ao lote 2, abaixou o coeficiente de aproveitamento para 2 e manteve a taxa de ocupação do solo no valor máximo permitido pela legislação, ou seja, 0,70 , sendo que o ângulo da edificação permaneceu em 0 grau. $\mathrm{O}$ resultado da alteração dos níveis de radiação solar na vizinhança imediata ao lote 2 , com a influência do Galapagos, é ilustrada na Figura 12, onde é possível notar, por meio de um comparativo entre os níveis de radiação solar do cenário morfológico atual de ocupação frente a um cenário morfológico evolutivo, que este maximiza os níveis de radiação solar da vizinhança imediata de maneira geral. O C.A. foi calculado para beneficiar o nível de radiação solar da vizinhança do empreendimento analisado, de forma que evita sombreamento nos empreendimentos vizinhos. A T.O., com 0,70, permite que seja respeitada uma distância mínima de três metros entre os empreendimentos. Em contrapartida, o Galapagos considerou tal distância aceitável para que o empreendimento possuísse maior área de cobertura disponível para aplicação de painéis fotovoltaicos.

O resultado das análises do lote 3 , em termos da radiação solar incidente por metro quadrado e da radiação solar incidente por área total de cobertura, é mostrado na Tabela 3 .

A análise das simulações da variação dos parâmetros isolados do lote 3 indica que a variação da taxa de ocupação para 0,50 gerou resposta ligeralmente superior em relação à radiação solar, quando é considerado o $\mathrm{kWh} / \mathrm{m}^{2}$ ano, como nas análises realizadas dos lotes anteriores. Porém, quando é analisada a radiação solar total incidente na área de cobertura, verifica-se que as variações com taxa de ocupação mais elevadas apresentam os melhores desempenhos, destacando-se as opções com valores máximos permitidos pela legislação vigente no Município de São Paulo.

Figura 12 - Comparação da radiação solar no lote 2 e vizinhança imediata, cenário morfológico atual de ocupação e cenário morfológico evolutivo (Galapagos)

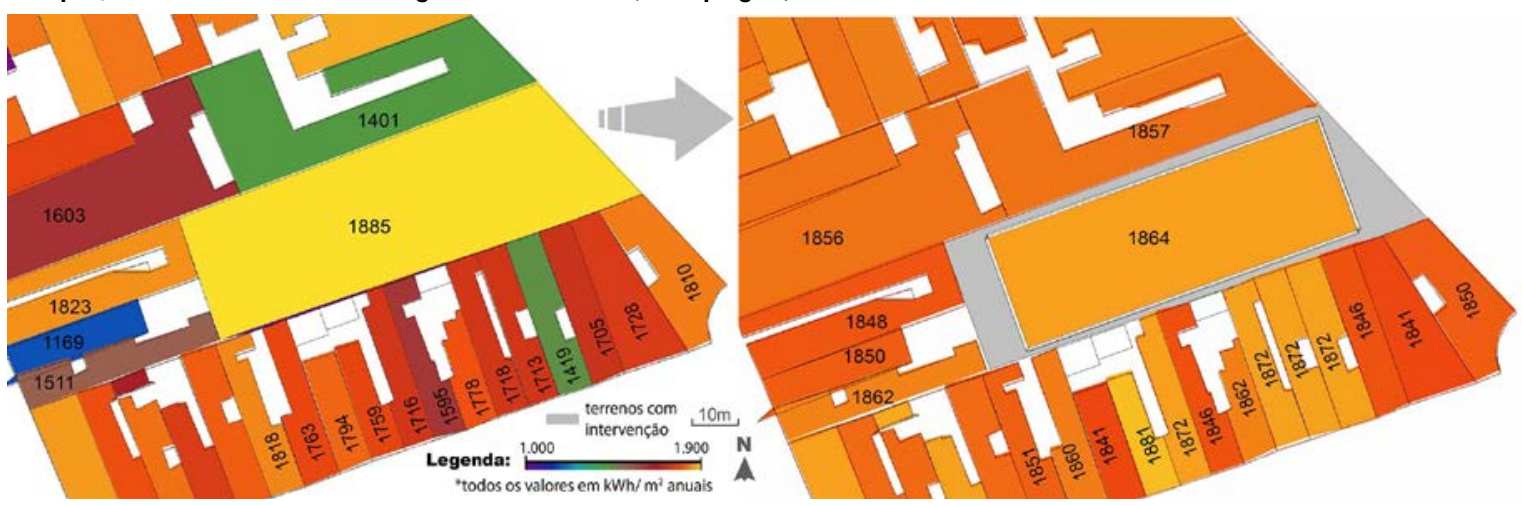

Tabela 3 - Lote 3: valores de incidência do nível de radiação solar por $\mathbf{m}^{\mathbf{2}}$ e cálculo da radiação solar incidente total

\begin{tabular}{|c|c|c|c|c|c|c|c|c|}
\hline & C.A. & T.O. & Âng. & $\begin{array}{c}\text { Radiação } \\
\text { solar } \\
\left(\mathbf{k W h} / \mathbf{m}^{2} /\right. \\
\text { ano })\end{array}$ & $\% *$ & $\begin{array}{c}\text { Área de } \\
\text { cobertura } \\
\left(\mathbf{m}^{2}\right)\end{array}$ & $\begin{array}{l}\text { Radiação solar } \\
\text { (kWh/área de } \\
\text { cobertura/ano) }\end{array}$ & $\% *$ \\
\hline C.A. 4; T.O. 0,70 & 4 & 0,70 & $\overline{0^{\circ}}$ & 1.880 & $1 \%$ & $2.740,0$ & 5.151 .200 & $35 \%$ \\
\hline C.A. 4; T.O. 0,60 & 4 & 0,60 & $0^{\circ}$ & 1.888 & $1 \%$ & $2.479,0$ & 4.680 .352 & $23 \%$ \\
\hline С.A. 4; T.O. 0,50 & 4 & 0,50 & $0^{\circ}$ & 1.889 & $1 \%$ & $2.020,0$ & 3.815 .780 & $0 \%$ \\
\hline С.А. 2; T.O. 0,70 & 2 & 0,70 & $0^{\circ}$ & 1.874 & $1 \%$ & $2.740,0$ & 5.134 .760 & $35 \%$ \\
\hline C.A. 1 ; T.O. 0,70 & 1 & 0,70 & $0^{\circ}$ & 1.862 & $0 \%$ & $2.740,0$ & 5.101 .880 & $34 \%$ \\
\hline Galapagos & 4 & 0,70 & $5^{\circ}$ & 1.880 & $1 \%$ & $2.740,0$ & 5.151 .200 & $35 \%$ \\
\hline
\end{tabular}

Nota: *\% percentual de incremento dos ganhos de radiação solar em relação ao pior resultado. 
O Galapagos, aplicado ao lote 3, manteve o coeficiente de aproveitamento e a taxa de ocupação nos valores máximos permitidos pela legislação municipal vigente (4 e 0,70 , respectivamente), deixando a edificação com uma densidade construída maior, e o ângulo da edificação foi modificado para 5 graus. $\mathrm{O}$ aumento da densidade construída, por meio da taxa de ocupação, aumenta a área de cobertura do empreendimento, favorecendo, assim, a geração de energia fotovoltaica, conforme já relatado. É importante ressaltar que o algoritmo genético Galapagos encontrou a melhor combinação entre os parâmetros urbanísticos para obtenção de melhores níveis de radiação solar, não apenas do empreendimento analisado, e sim de sua vizinhança como um todo, conforme ilustrado na Figura 13. Nota-se, por meio de um comparativo entre os níveis de radiação solar do cenário morfológico atual de ocupação frente a um cenário morfológico evolutivo, que este maximiza os níveis de radiação solar da vizinhança imediata de maneira geral, assim como no próprio lote analisado.

O resultado das análises do lote 4 , em termos da radiação solar incidente por metro quadrado e da radiação solar incidente por área total de cobertura, é mostrado na Tabela 4.

A análise das simulações de variação dos parâmetros isolados do lote 4 indica que a variação da taxa de ocupação para 0,60 gerou resposta ligeralmente melhor em relação à radiação solar, quando é considerado o kWh/m2ano. Porém, quando é analisada a radiação solar total incidente sobre a cobertura, a variação com parâmetros urbanísticos (C.A. e T.O.) máximos permitidos pela legislação vigente no Município de São Paulo possui melhor resposta em relação aos níveis de radiação solar.

\section{Figura 13 - Comparação da radiação solar no lote 3 e vizinhança imediata, cenário morfológico atual de ocupação e cenário morfológico evolutivo (Galapagos)}

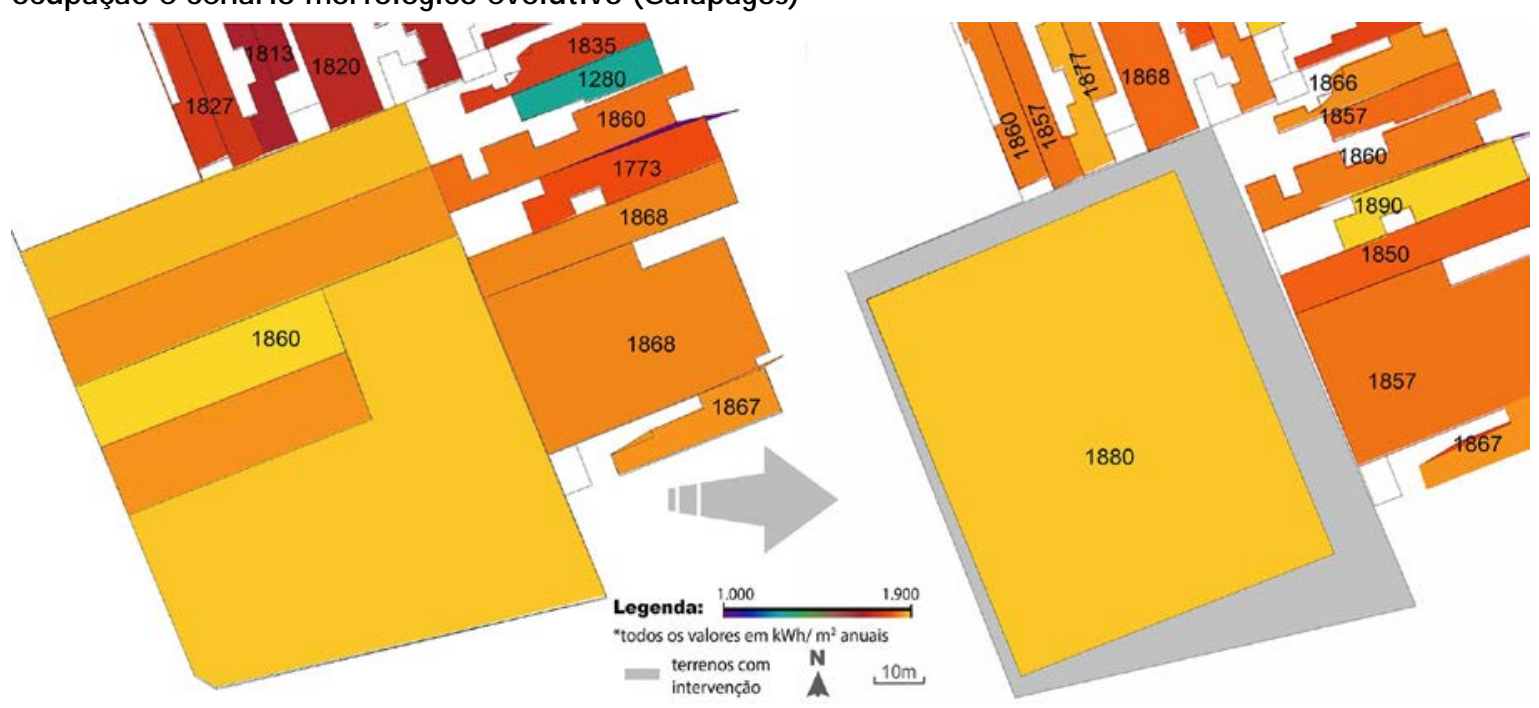

Tabela 4 - Lote 4: valores de incidência do nível de radiação solar por $\mathbf{m}^{\mathbf{2}}$ e cálculo da radiação solar incidente total

\begin{tabular}{|c|c|c|c|c|c|c|c|c|}
\hline & C.A. & T.O. & Âng. & $\begin{array}{l}\text { Radiação } \\
\text { solar } \\
\left(\mathbf{k W h} / \mathbf{m}^{2} /\right. \\
\text { ano) }\end{array}$ & $\% *$ & $\begin{array}{c}\text { Área de } \\
\text { cobertura } \\
\left(\mathbf{m}^{2}\right)\end{array}$ & $\begin{array}{c}\text { Radiação solar } \\
\text { (kWh/área de } \\
\text { cobertura/ano) }\end{array}$ & $\% *$ \\
\hline C.A. 2; T.O. 0,85 & 2 & 0,85 & $0^{\circ}$ & 1.871 & $1 \%$ & 375,0 & 701.625 & $102 \%$ \\
\hline C.A. 2 ; T.O. 0,70 & 2 & 0,70 & $0^{\circ}$ & 1.867 & $1 \%$ & 305,0 & 569.435 & $64 \%$ \\
\hline C.A. 2 ; T.O. 0,60 & 2 & 0,60 & $0^{\circ}$ & 1.872 & $1 \%$ & 263,0 & 492.336 & $42 \%$ \\
\hline C.A. 1 ; T.O. 0,85 & 1 & 0,85 & $0^{\circ}$ & 1.851 & $0 \%$ & 375,0 & 694.125 & $100 \%$ \\
\hline C.A. 0,$5 ;$ T.O. 0,85 & 0,5 & 0,40 & $0^{\circ}$ & 1.851 & $0 \%$ & 187,5 & 347.063 & $0 \%$ \\
\hline Galapagos & 1 & 0,70 & $0^{\circ}$ & 1.865 & $1 \%$ & 305,0 & 568.825 & $64 \%$ \\
\hline
\end{tabular}

Nota: *\%percentual de incremento dos ganhos de radiação solar em relação ao pior resultado. 
O Galapagos, aplicado ao lote 4, abaixou o coefiente de aproveitamento para 1 e a taxa de ocupação para 0,70 , sendo o ângulo da edificação mantido em 0 grau. $\mathrm{O}$ valor da T.O. mostra que, possivelmente, 0,70 é um valor máximo adequado, do ponto de vista da geração fotovoltaica na cobertura, para manter uma distância entre as edificações, quando C.A é até 4 . O resultado da alteração dos níveis de radiação solar na vizinhança imediata aos lotes 4 e 5, com a influência do Galapagos, é ilustrada na Figura 14. Nota-se, pelo comparativo entre os níveis de radiação solar do cenário morfológico atual de ocupação frente a um cenário morfológico evolutivo, que este maximiza os níveis de radiação solar na vizinhança imediata de maneira geral. O resultado das análises do lote 5 , em termos da radiação solar incidente por metro quadrado e da radiação solar incidente por área total de cobertura, é mostrado na Tabela 5.

A análise das simulações da variação dos parâmetros isolados do lote 5 indica que a variação da taxa de ocupação para 0,50 gerou melhor resposta em relação à radiação solar, quando é considerado o kWh/m2ano. Porém, quando é analisada a radiação solar total incidente sobre a cobertura, a variação com parâmetros urbanísticos (C.A. e T.O.) máximos permitidos pela legislação vigente no Município de São Paulo possui melhor resposta em relação aos níveis de radiação solar.

O Galapagos, aplicado ao lote 5, abaixou o coeficiente de aproveitamento e a taxa de ocupação para 1 e 0,60, respectivamente, e o ângulo da edificação foi modificado para 353 graus. A diminuição do CA gera menor altura de gabarito do empreendimento, beneficiando o acesso à radiação solar dos empreendimentos vizinhos. O resultado da alteração dos níveis de radiação solar na vizinhança imediata ao lote 4 e do 5 , com a influência do Galapagos, é ilustrado na Figura 14.

\section{Análise do conjunto de resultados}

Ao comparar as simulações das variações dos parâmetros isolados, no conjunto de lotes analisados, constatou-se que os resultados convergem quando analisados por radiação solar incidente por metro quadrado e por radiação solar incidente por área total de cobertura.

\section{Figura 14 - Comparação da radiação solar nos lotes 4 e 5 e vizinhança imediata, cenário morfológico} atual de ocupação e cenário morfológico evolutivo (Galapagos)

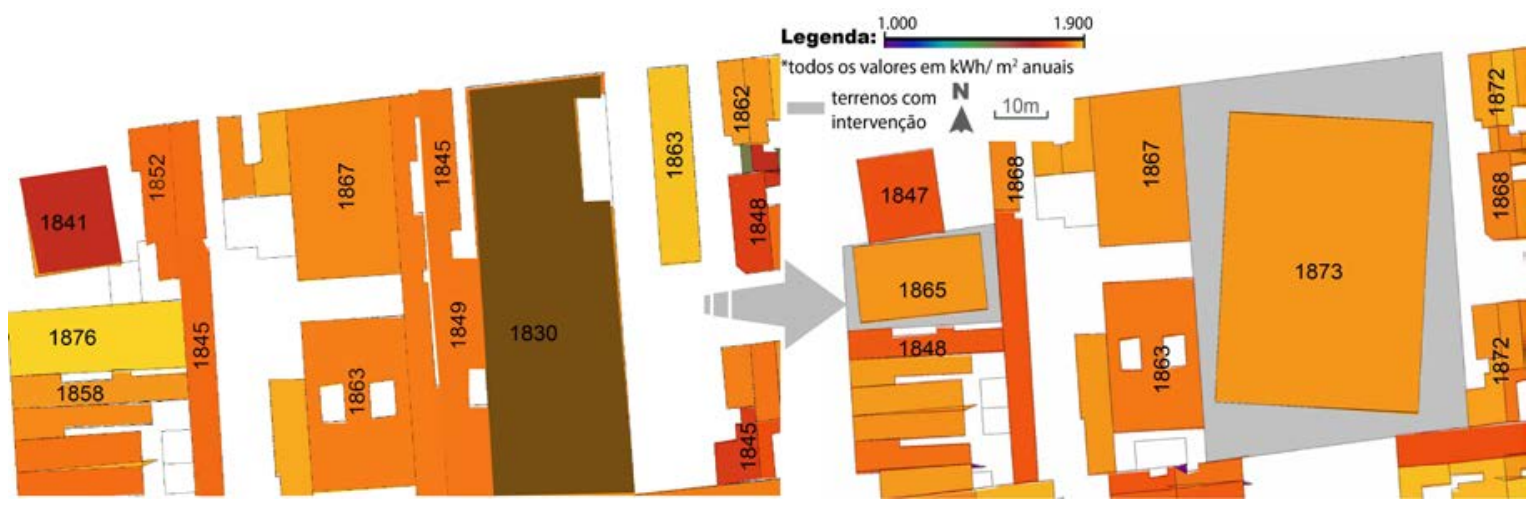

Tabela 5 - Lote 5: valores de incidência do nível de radiação solar por $\mathbf{m}^{\mathbf{2}}$ e cálculo da radiação solar incidente total

\begin{tabular}{|c|c|c|c|c|c|c|c|c|}
\hline & C.A. & T.O. & Âng. & $\begin{array}{c}\text { Radiação } \\
\text { solar } \\
\left(\mathbf{k W h} / \mathbf{m}^{2} / \mathbf{a n o}\right)\end{array}$ & $\% *$ & $\begin{array}{c}\text { Área de } \\
\text { cobertura } \\
\left(\mathbf{m}^{2}\right)\end{array}$ & $\begin{array}{c}\text { Radiação solar } \\
\text { (kWh/área de } \\
\text { cobertura/ano) }\end{array}$ & $\% *$ \\
\hline C.A. 2; T.O. 0,70 & 2 & 0,70 & $0^{\circ}$ & 1.878 & $0 \%$ & $2.157,0$ & 4.050 .846 & $100 \%$ \\
\hline C.A. 2; T.O. 0,60 & 2 & 0,60 & $0^{\circ}$ & 1.885 & $1 \%$ & $1.857,0$ & 3.500 .445 & $73 \%$ \\
\hline C.A. 2; T.O. 0,50 & 2 & 0,50 & $0^{\circ}$ & 1.889 & $1 \%$ & $1.534,0$ & 2.897 .726 & $43 \%$ \\
\hline C.A. 1 ; T.O. 0,70 & 1 & 0,70 & $0^{\circ}$ & 1.874 & $0 \%$ & $2.157,0$ & 4.042 .218 & $100 \%$ \\
\hline C.A. 0,5 ; T.O. 0,70 & 0,5 & 0,35 & $0^{\circ}$ & 1.874 & $0 \%$ & $1.078,5$ & 2.021 .109 & $0 \%$ \\
\hline Galapagos & 1 & 0,60 & $353^{\circ}$ & 1.873 & $0 \%$ & $1.857,0$ & 3.478 .161 & $20 \%$ \\
\hline
\end{tabular}

Nota: *\%percentual de incremento dos ganhos de radiação solar em relação ao pior resultado. 
Quando a análise é feita por radiação solar incidente por metro quadrado, todos os melhores resultados referem-se a taxas de ocupação menores, já que, dessa forma, os volumes construídos têm gabarito de altura mais elevado e, portanto, estão mais expostos à radiação solar incidente por metro quadrado.

Porém, quando a análise é feita considerando-se a radiação solar incidente por área total de cobertura, todos os melhores resultados encontram-se nas variações que empregam, sobretudo, maiores taxas de ocupação e coeficientes de aproveitamento, segundo os valores permitidos pela legislação vigente no Município de São Paulo. A Figura 15 ilustra um gráfico comparativo entre as simulações das variações dos parâmetros isolados, no conjunto dos lotes analisados quanto à radiação solar incidente por área total de cobertura, já que, dessa forma, é possível quantificar, de fato, o montante total de aproveitamento do potencial fotovoltaico nos respectivos empreendimentos.
Os resultados obtidos pelo algoritmo genético Galapagos, de forma geral, não condizem com os resultados obtidos com a variação dos parâmetros isolados, pois quando o parâmetro é variado de forma isolada, apenas o nível da radiação solar da cobertura do empreendimento analisado é considerado. Ou seja, a parametrização encontra o melhor desempenho para o empreendimento analisado, de forma individual, sem considerar seus impactos no acesso à radiação solar do entorno. Já na simulação do Galapagos, o algoritmo genético busca uma melhor combinação entre os parâmetros, de forma que encontre o melhor nível de radiação solar incidente na cobertura do empreendimento, mas mantendo níveis adequados na vizinhança. As simulações no Galapagos que encontraram os melhores resultados em relação ao nível de radiação solar referem-se à taxa de ocupação de 0,70 combinada com densidades construídas máximas ou intermediárias, conforme ilustra o gráfico da Figura 16.

\section{Figura 15 - Incremento dos ganhos de radiação solar incidente por área total de cobertura nas análises isoladas}

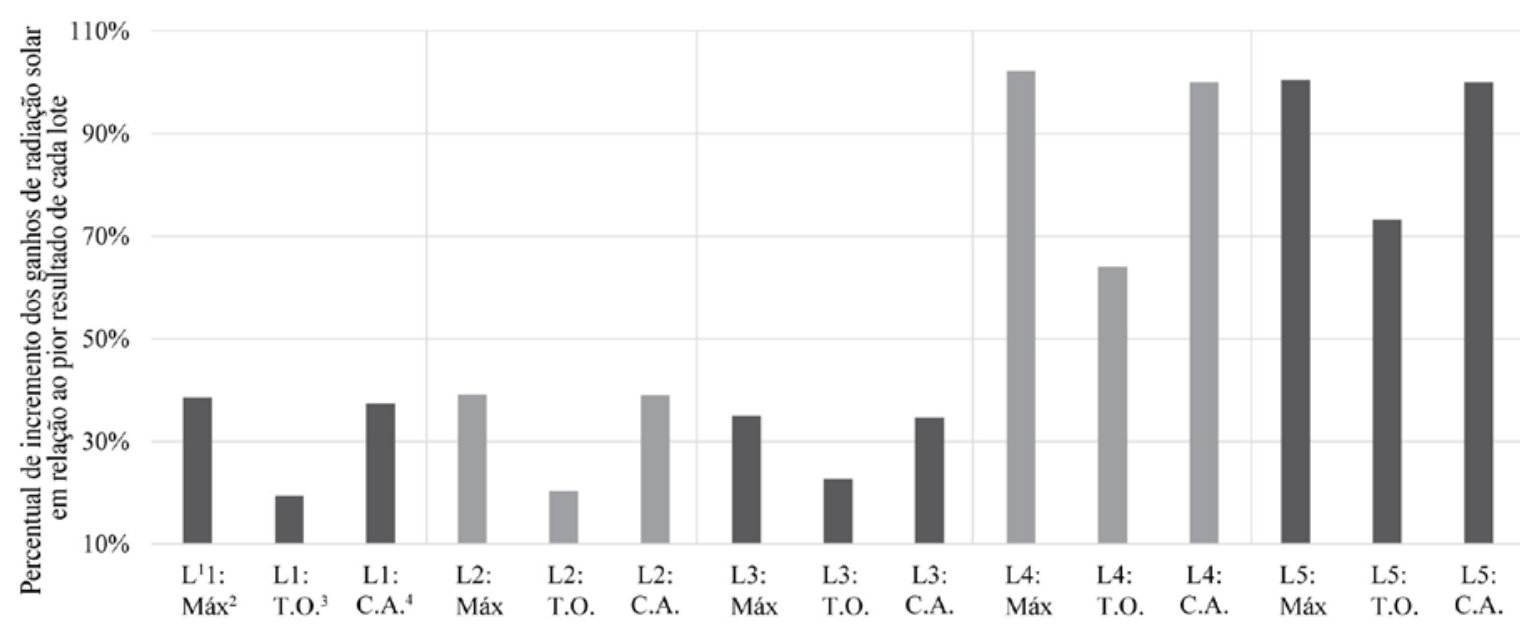

Nota: Legenda:

\footnotetext{
${ }^{1}$ L: Lote;

${ }^{2}$ Máx: Resultado das simulações com aplicação dos parâmetros urbanisticos com valores máximos permitidos pela legislação vigente no Município de São Paulo;

${ }^{3}$ T. O.: Resultado das simulações com aplicação da variação da taxa de ocupação com valores inferiores que 0 permitido pela legislação vigente no Município de São Paulo; e

${ }^{4}$ C. A.: Resultado das simulações com aplicação da variação do coeficiente de aproveitamento com valores inferiores que o permitido pela legislação vigente no Município de São Paulo.
} 
Figura 16 - Gráfico comparativo entre simulações Galapagos para C.A e T.O.

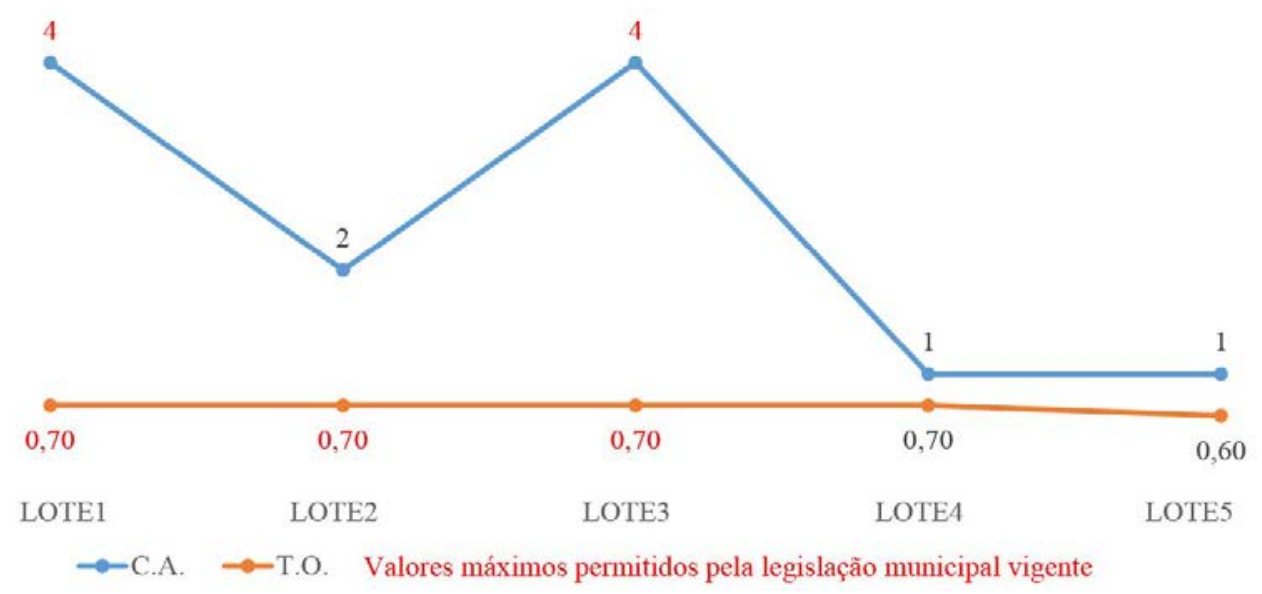

A análise dos resultados das simulações das variações dos parâmetros isolados mostra que, conforme Martins et al. (2014) ressaltam, quanto maior o número de pavimentos, maior será a radiação solar recebida pela edificação, além de que a distância entre as edificações é benéfica à maximização dos níveis de radiação solar incidente na cobertura das edificações, por meio da adequação da taxa de ocupação. E por fim, valores máximos de taxa de ocupação regulam a área de cobertura disponível para aplicação de painéis fotovoltaicos, essencial para maximizar o potencial de energia solar fotovoltaica.

Já a análise dos resultados das simulações dos parâmetros combinados, realizadas com o algoritmo genético Galapagos, condiz com os autores Martins et al. $(2016,2014)$ a respeito da distância entre as edificações. Os resultados mostram que é necessário afastar as edificações em um tecido urbano como um todo, observando-se valores mínimos de 0,70 de taxa de ocupação, nos casos estudados. Porém, quanto ao número de pavimentos, a simulação com o Galapagos não confirma o estudo de Martins et al. (2014), no sentido de que quanto maior o número de pavimentos, maior será a radiação solar recebida. Os resultados das simulações realizadas no presente estudo mostram que valores máximos de coeficiente de aproveitamento e, consequentemente, maiores gabaritos de altura, para certos empreendimentos, em uma dada área urbana analisada, não são os mais adequados para a vizinhança como um todo, já que edificações com gabaritos superiores causam sombreamentos nas edificações vizinhas, o que reduz o desempenho do entorno quanto ao aproveitamento da radiação solar.

\section{Conclusões}

O método desenvolvido permitiu realizar, ainda que de forma simplificada, a análise integrada dos parâmetros urbanísticos previstos na legislação do Município de São Paulo com dados de radiação solar, em uma escala de unidade de vizinhança. Ressalta-se a limitação deste trabalho por se tratar de um estudo de caso, além de outros fatores que se encontram fora do escopo de análise, como a presença de vegetações, que podem gerar sombreamento adicional na cobertura das edificações, especialmente daquelas com gabaritos inferiores. Também não se procedeu à análise do potencial de aproveitamento fotovoltaico nas fachadas das edificações, que poderiam modificar os resultados desse estudo.

Verificou-se, ainda, que o urbanismo paramétrico, combinado com o algoritmo genético Galapagos, constitui uma ferramenta prática para aplicação em planejamento e projeto urbano, por permitir a simulação de diferentes valores para os parâmetros urbanísticos considerados, frente ao aproveitamento da energia solar fotovoltaica.

Os resultados das simulações realizadas, em específico, mostraram que o emprego dos valores máximos permitidos pela legislação vigente no Município de São Paulo para coeficiente de aproveitamento e taxa de ocupação do solo nem sempre são adequados a uma política de ampla inserção de sistemas fotovoltaicos em coberturas de edificações em bairros como um todo, especialmente em zonas onde é permitido taxa de ocupação máxima de 0,85 . Além do que, quando se considera o coeficiente de aproveitamento, muito se depende da morfologia do entorno para se obter valores de radiação solar satisfatórios em escala de vizinhança. 
Dessa forma, o estudo indica que a definição de uma possível política energética municipal para aproveitamento fotovoltaico na cobertura de edificações passa pela análise da viabilidade e do desempenho de soluções de geração de energia concentradas ou distribuídas no território urbano. Para isso, faz-se necessária a definição dos valores mínimos, básicos e máximos dos parâmetros urbanísticos também com base nessa funcionalidade. Em estudos subsequentes, esperase ponderar valores intermediários do coeficiente de aproveitamento e da taxa de ocupação, bem como associar à presente análise a consideração de aspectos microclimáticos urbanos, tais como condições de sombreamento e ventilação, em áreas sujeitas ao adensamento populacional e construído e à verticalização.

\section{Referências}

ANTON, I.; TǍNASE, D. Informed Geometries. Parametric Modelling and Energy Analysis in Early Stages of Design. Energy Procedia, v. 85, p. 9-16, 2016.

BRASIL. Resolução Normativa no 482, de 2012 da ANEEL. ANEEL, 2012.

BRASIL. Resolução Normativa no 687, de 2015 da ANEEL. ANEEL, 2015.

EMPRESA DE PESQUISA ENERGÉTICA. Nota Técnica 001/17: projeção da demanda de energia elétrica. Brasil, 2017.

FEARNSIDE, P. M. Social Impacts of Brazil's Tucuruí Dam. Environmental Management, v. 24, n. 4, p. 483-495, 1999.

FEARNSIDE, P. M. Dams in the Amazon: Belo Monte and Brazil's hydroelectric development of the Xingu River Basin. Environmental Management, v. 38, n. 1, p. 16-27, 2006.

FUTCHER, J. A.; MILLS, G. The Role of Urban Form As an Energy Management Parameter. Energy Policy, v. 53, p. 218-228, fev. 2013.

GAVIRIA, L. R.; PEREIRA, F. O. R.; MIZGIER, M. O. Influência da Configuração Urbana na Geração Fotovoltaica Com Sistemas Integrados às Fachadas. Ambiente Construído, Porto Alegre, v. 13, n. 4, p. 07-23, dez. 2013.

GOOGLE. Google Earth: versão 7.3.0.3832, 2017.

HARGREAVES, A. et al. Forecasting How Residential Urban Form Affects the Regional Carbon Savings and Costs of Retrofitting and Decentralized Energy Supply. Applied Energy, v. 186, p. 549-561, 2017.
HUI, S. C. M. Low Energy Building Design in High Density Urban Cities. Renewable Energy, v. 24, n. 3-4, p. 627-640, 2001.

MARINS, K. R. de C. C.; ROMÉRO, M. de A. Integração de Condicionantes de Morfologia Urbana no Desenvolvimento de Metodologia Para Planejamento Energético Urbano. Ambiente Construído, Porto Alegre, v. 12, n. 4, p. 117-137, out./dez. 2012.

MARINS, K. R. de C. C.; ROMÉRO, M. de A. Urban and Energy Assessment from a Systemic Approach of Urban Morphology, Urban Mobility, and Buildings: Case Study of Agua Branca in Sao Paulo. Journal of Urban Planning and Development, v. 139, n. 4, p. 280-291, dez. 2013.

MARTINO, J. A. de; CELANI, G. Sistema Generativo Evolutivo Como Método no Processo Criativo. In: CONFERENCE OF THE IBEROAMERICAN SOCIETY OF DIGITAL GRAPHICS - SIGRADI: DESIGN IN FREEDOM, 18., 2014. Proceedings... 2014.

MARTINS, T. A. de L. et al. Sensitivity Analysis of Urban Morphology Factors Regarding solar Energy Potential of Buildings in a Brazilian Tropical Context. Solar Energy, v. 137, p. 11-24, 2016.

MARTINS, T. A. de L. et al. From Solar Constraints to Urban Design Opportunities: optimization of built form typologies in a Brazilian tropical city. Energy and Buildings, v. 76, p. 4356, 2014.

MUNIZ-GÄAL, L. P. et al. Parâmetros Urbanísticos e o Conforto Térmico de Cânions Urbanos: o exemplo de Campinas, SP. Ambiente Construído, Porto Alegre, v. 18, n. 2, p. 177-196, abr./jun. 2018.

NG, E. et al. Improving the Wind Environment in High-Density Cities by Understanding Urban Morphology and Surface Roughness: a study in Hong Kong. Landscape and Urban Planning, v. 101, n. 1, p. 59-74, 2011.

\section{PREFEITURA DO MUNICÍPIO DE SÃO \\ PAULO. Plano Diretor Estratégico do Município de São Paulo. Brasil, 2014.}

PREFEITURA DO MUNICÍPIO DE SÃO PAULO. Lei de Parcelamento, uSo e Ocupação do Solo. Brasil, 2016.

\section{PREFEITURA DO MUNICÍPIO DE SÃO PAULO. GeoSampa Prefeitura de São Paulo. Disponível em: $<$ www.geosampa.prefeitura.sp.gov.br>. Acesso em: 2 maio 2017.}


ROBERT MCNEEL \& ASSOCIATES.

Rhinoceros: versão 5.0, 2012a.

ROBERT MCNEEL \& ASSOCIATES.

Grasshoper: versão 5.0, 2012b.

SANTOS, I. G. dos; AUER, T.; SOUZA, R. V. G. de. Optimized Indoor Daylight for Tropical Dense Urban Environments. Ambiente Construído, Porto Alegre, v. 17, n. 3, p. 87-102, jul./set. 2017.

SARRALDE, J. J. et al. Solar Energy and Urban Morphology: scenarios for increasing the renewable energy potential of neighbourhoods in London. Renewable Energy, v. 73, p. 10-17, jan. 2015.

SCALCO, V. A.; PEREIRA, F. O. R.; RIGATTI, D. Impacto de Novas Edificações na Vizinhança: proposta de método para a análise das condições de iluminação natural e de insolação. Ambiente Construido, Porto Alegre, v. 10, n. 2, p. 171-187, abr./jun. 2010.
SOLEMMA. Diva: versão 4.0, 2016.

SOLEMMA LLC. Solemma Diva. Disponível em: $<$ https://www.solemma.com/Diva.html $>$. Acesso em: 13 set. 2018.

WALTON, D. et al. Urban Design

Compendium. London: English Partnerships e The Housing Corporation, 2007.

\section{Agradecimentos}

O presente trabalho foi realizado com apoio da Coordenação de Aperfeiçoamento de Pessoal de Nível Superior - Brasil (Capes) - Código de Financiamento 001.

\section{Carolina Girotti}

Departamento de Engenharia de Construção Civil, Escola Politécnica | Universidade de São Paulo | Av. Prof. Almeida Prado, 83, Trav. 2, Cidade Universitária | São Paulo - SP - Brasil | CEP 05508-070 | Tel.: (011) 3091-5107 | E-mail: cgirotti@usp.br

\section{Karin Regina de Castro Marins}

Departamento de Engenharia de Construção Civil, Escola Politécnica | Universidade de São Paulo | E-mail: karin.marins@usp.br

\section{Arthur Hunold Lara}

Departamento de Tecnologia da Arquitetura, Faculdade de Arquitetura e Urbanismo | Universidade de São Paulo | Rua do Lago, 876, Cidade Universitária | São Paulo - SP - Brasil | CEP 05508-080 | Tel.: (011) 3091-4570 | E-mail: arthurlara@usp.br

\section{Revista Ambiente Construído}

Associação Nacional de Tecnologia do Ambiente Construído

Av. Osvaldo Aranha, 99 - 3o andar, Centro

Porto Alegre - RS - Brasil

CEP $90035-190$

Telefone: +55 (51) 3308-4084

Fax: +55 (51) 3308-4054

www. seer. ufrgs. br/ ambienteconstruido

E-mail: ambienteconstruido@ufrgs.br

This is an open-access article distributed under the terms of the Creative Commons Attribution License. 